\title{
Weldability and Mechanical Behavior of GTD-141
}

\author{
G. Feng ${ }^{1}$, A. Peck ${ }^{1}$, S. J. Balsone ${ }^{1}$ and T. Carneiro ${ }^{2}$ \\ ${ }^{1}$ GE Energy, P.O. Box 648, Greenville, SC 29602 \\ ${ }^{2}$ Reference Metals Company, 1000 Old Pond Road, Bridgeville, PA 15017
}

Keywords: nickel-base alloys, GTD-111 ${ }^{\mathrm{TM}}$, GTD-141, weldability, microstructure, mechanical property

\begin{abstract}
GTD-141 is an Nb-modified derivative of GTD- $111^{\mathrm{TM}}$, in which $\mathrm{Nb}$ replaces $\mathrm{Ta}$ on a one-for-one atomic percent basis. Extensive development work indicates that GTD-141 has similar mechanical properties and castability as the GTD- $111^{\mathrm{TM}}$ baseline alloy. In the present study, GTD-141 and GTD-111 ${ }^{\mathrm{TM}}$ weld joints were compared. The effects of $\mathrm{Nb}$ for $\mathrm{Ta}$ substitution on the weldability, low cycle fatigue (LCF) and microstructure were discussed. The results indicated that $\mathrm{Nb}$ substitution for Ta did not have any detrimental effect on the fusion zone and heat affected zone (HAZ) microstructures and LCF properties. With nearly $60 \mathrm{vol} \%$ gamma prime, GTD-141 would be as "unweldable" as the GTD- $111^{\mathrm{TM}}$, but crack-free weld joints could be achieved by using advanced electron beam (EB) welding process. It was also found that GTD-141 helped to reduce HAZ cracks during hardfacing. The benefit is obtained from the improved ductility due to the $\mathrm{Nb}$ substitution.
\end{abstract}

\section{Introduction}

GTD- $111^{\mathrm{TM}}$ is a precipitation-strengthened nickel-base superalloy developed by GE for large industrial gas turbine hot gas path applications. The alloy is a modification of Rene' 80 in which Ta was substituted for some of the Mo in order to change the MC carbide chemistry to primarily TaC. Switching to TaC reduced Type I hot corrosion pitting attack associated with the localized concentration of Mo and $\mathrm{W}$ in the MC carbide. The original development work also included alloys with other strong $\mathrm{MC}$ carbide formers such as $\mathrm{Nb}$ and $\mathrm{Hf}$, added either in place of or in combination with $\mathrm{Ta}[1,2]$. In one such alloy, GTD-141, Nb was substituted for Ta on a one-for-one atomic percent basis. Extensive development work indicated that the mechanical properties and castability of the GTD-141 were essentially identical to the GTD-111 ${ }^{\mathrm{TM}}$ baseline alloy, however, weldability and weld joint properties were not investigated.

Niobium can have a mixed effect on the formation of welding cracks in different alloy systems. For example, it has been shown that the substitution of $\mathrm{Nb}$ with $\mathrm{Ta}$ in cast Alloy 718 on a one-for-one atomic percent basis could reduce heat-affected zone (HAZ) liquation cracking and the weld fusion zone solidification cracking [3]. This is because Ta substitution reduces the difference between the liquidus temperature and the eutectic temperature. Due to the high $\mathrm{Nb}$ content in Alloy 718 $(\sim 5 \%), \mathrm{Nb}$ tends to segregate to inter-dendritic region, which extends the solidification range and promotes the Nb-rich eutectic precipitation in the final stage of the solidification [4]. On the other hand, it is well known that Alloy 718 is highly resistant to strain-aging cracking during post weld heat treatment. This is attributed to a sluggish gamma double prime precipitation due to the high $\mathrm{Nb}$ and low $\mathrm{Al}$ and $\mathrm{Ti}$ content in Alloy 718. The effects of $\mathrm{Nb}$ on Alloy 718 weld joints include: (i) promotion of fusion zone solidification cracking, (ii) promotion of HAZ liquation cracking, and (iii) reduced strainaging cracking. Unlike Alloy 718, $\mathrm{Ta}+\mathrm{Nb}$ content in GTD$111^{\mathrm{TM}}$ is only $3 \%$ compared to $5 \%$ in Alloy 718 . It was reported that there was only $10^{\circ} \mathrm{F}$ difference in solidification range between Ta-containing alloy and $\mathrm{Nb}$-containing alloy when $\mathrm{Nb}$ was substituted for Ta on a one-for-one atomic percent basis in an alloy system similar to GTD-111 ${ }^{\mathrm{TM}}[5]$. Based on this, Nbmodified GTD- $111^{\mathrm{TM}}$ should have less tendency to form solidification cracks and HAZ liquation cracks than Alloy 718. Furthermore, GTD- $111^{\mathrm{TM}}$ is a different alloy system from Alloy 718. It contains more strong precipitation hardening elements like $\mathrm{Al}$ and $\mathrm{Ti}$. The effect of these elements on the precipitation reaction in the HAZ and the overall mechanical properties of the welded alloy need to be verified.

In the present study, the LCF properties and microstructure of GTD- $111^{\mathrm{TM}}$ and GTD-141 weld joints are compared. Cracking susceptibility, weld joint microstructure, and LCF behavior are evaluated. The effect of $\mathrm{Nb}$ on weldability of different welding process is discussed.

\section{Materials \& Experimental Procedures}

The materials in this investigation were GTD-111 ${ }^{\mathrm{TM}}$ and GTD141 cast slabs. In GTD-141, $\mathrm{Nb}$ was substituted for $\mathrm{Ta}$ on a one-for-one atomic percent basis. Both directionally solidified (DS) and equiaxed (EA) alloys were evaluated. The compositions of the two alloys are given in Table 1 . The dimensions of the slabs were approximately $228 \times 127 \times 22 \mathrm{~mm}$. The evaluations consisted of weld joint LCF tests, hardfacing tests, Spot Varestraint tests, and metallography using optical microscope and SEM.

Prior to testing, all coupons were solution heat treated in vacuum. Weld blanks were cut by wire-EDM from the slabs and welded using a GE developed electron beam (EB) welding 
process. The weldments were post-weld solution treated and aged to yield optimum mechanical properties. LCF tests were carried out using round bar specimens with the weld joint in the middle of the gage length. Axial-axial strain-controlled LCF tests were conducted at $1600 \mathrm{~F}$. The tests were run at a frequency of $0.167 \mathrm{~Hz}$ with a two minute hold time at the maximum compressive strain. A strain ratio of $A=-1$ was used $(\mathrm{A}=$ strain amplitude/mean strain).

Table 1: Compositions of Testing Materials, wt \%

\begin{tabular}{|l|l|l|}
\hline Element & GTD-141 & GTD-111 $^{\text {TM }}$ \\
\hline $\mathrm{C}$ & 0.09 & 0.10 \\
\hline $\mathrm{Cr}$ & 13.80 & 13.96 \\
\hline $\mathrm{Co}$ & 9.4 & 9.49 \\
\hline $\mathrm{W}$ & 3.75 & 3.82 \\
\hline $\mathrm{Mo}$ & 1.47 & 1.48 \\
\hline $\mathrm{Nb}$ & 1.40 & 0.07 \\
\hline $\mathrm{Ta}$ & $<0.01$ & 3.15 \\
\hline $\mathrm{Ti}$ & 4.79 & 5.00 \\
\hline $\mathrm{Al}$ & 2.83 & 3.03 \\
\hline $\mathrm{Zr}$ & 0.001 & -.007 \\
\hline $\mathrm{B}$ & 0.011 & 0.014 \\
\hline $\mathrm{Hf}$ & $<0.01$ & $<0.01$ \\
\hline
\end{tabular}

Laser hardfacing was conducted on GTD-141 and GTD-111 ${ }^{\mathrm{TM}}$ coupons. The weld powder was Coast Metal 64 (CM64). The weld build-up was approximately $4 \mathrm{~mm}$ thick and covered an area of $12 \times 19 \mathrm{~mm}$. After deposition the coupons were rapidly heated to solution temperature and quenched to room temperature in order to check cracking susceptibilities.

To evaluate the effect of $\mathrm{Nb}$ substitution on $\mathrm{HAZ}$ liquation cracking susceptibility, Spot-Varestraint tests were conducted. The samples included DS and equiaxed GTD-141 and GTD$111^{\mathrm{TM}}$ baseline. All the samples were in the solution heattreated condition. The samples were $25 \mathrm{~mm} \times 152 \mathrm{~mm}$ flat strips with a thickness of $6 \mathrm{~mm}$. In the test, HAZ liquation cracking is induced by bending the sample around a die block of fixed radius to a given strain level immediately after a spot weld has been made on the surface of the sample. After testing, the number of cracks in the fusion zone and in the HAZ, and the maximum crack distance (MCD) were determined using a microscope at $40 \mathrm{X}$ magnification.

\section{Results \& Discussion}

\section{Directional Solidified Alloys}

The cross-sections of the weld joints were inspected using metallography samples cut adjacent to the gage section of LCF specimens. The cross-section views of the weld joints made from the two alloys are shown in Fig. 1. Since the specimens are in the fully heat-treated conditions, the HAZ is not visible using optical microscopy. Typical HAZ widths of the EB weld joints ranged from 0.15 to $0.30 \mathrm{~mm}$. No obvious welding defects were observed from the joints. While both alloys exhibited a duplex gamma prime structure consisting of large primary gamma prime particles left by the partial solution with a background of fine gamma prime formed during the aging cycle, less primary gamma prime was observed in the DS GTD-141, especially in the HAZ as shown in Fig. 2. This may be attributed to the slightly lower gamma prime solvus temperature due to Ta substitution.

The Manson-Coffin relation can be used to describe the LCF behavior of GTD-111 ${ }^{\mathrm{TM}}$ weld joints: [6]

$$
\Delta \varepsilon_{\mathrm{p}}=\mathrm{m}\left(\mathrm{N}_{\mathrm{f}}\right)^{\mathrm{c}}
$$

where $\Delta \varepsilon_{\mathrm{p}}$ is plastic strain range, $\mathrm{N}_{\mathrm{f}}$ is cycles to failure, and $\mathrm{m}$ and $c$ are constants. Fig. 3 shows cycles to failure of DS GTD$111^{\mathrm{TM}}$ and DS GTD-141 EB weld joints as a function of plastic strain range. It can be seen that, from the limited data, DS GTD141 appears to have a longer LCF life than DS GTD-111 ${ }^{\mathrm{TM}}$. The steep slope of the Weibull plot for DS GTD-141 weld joint is indicative of consistent quality of the weld joint. In contrast, the Weibull plot of DS GTD-111 joint exhibited a mixed failure mode. It should be mentioned that the Weibull analysis is included to distinguish the small difference between the two groups of samples. However, due to the limited sample size, statistical analysis revealed no significant difference between these two groups.

The LCF life of the weld joint at high temperature strongly depends on the combination of ductility and strength of the material. The welded joint acting as a metallurgical notch often provides the stress concentration site for fatigue crack initiation due to the metallurgical conditions of the weld/HAZ, and the presence of the welding defects. In the present study, most specimens failed in the weld metal or at the weld/HAZ interface. SEM fractographs taken from the fracture surfaces of EB weld
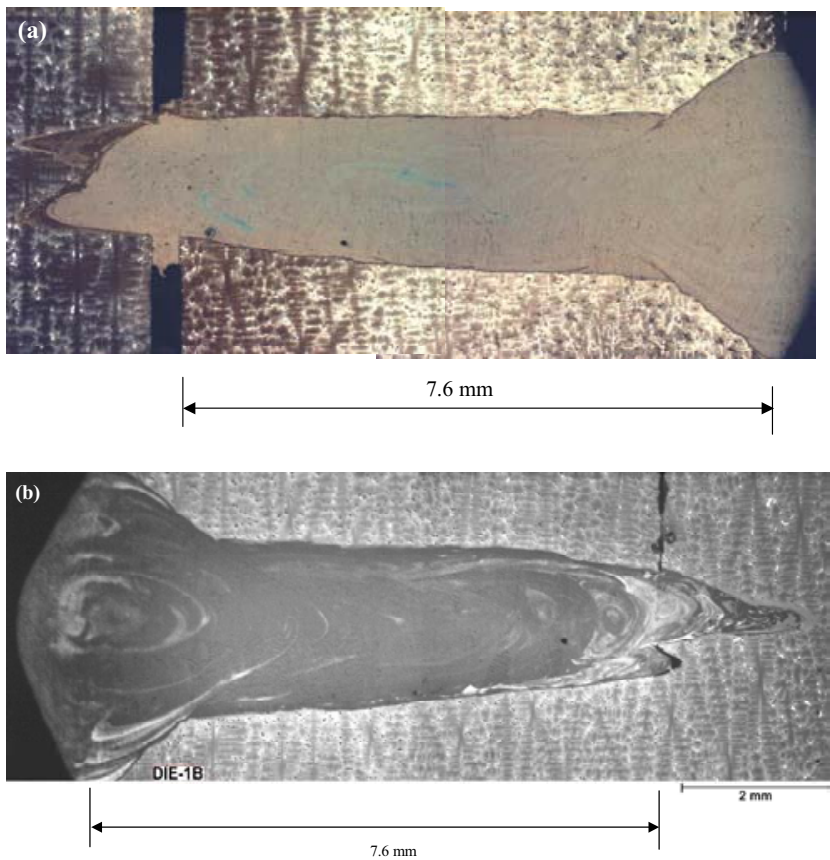

Figure 1: Cross-section view of (a) DS GTD- $111^{\mathrm{TM}}$ EB weld joint, (b) DS GTD-141 EB weld joint. 


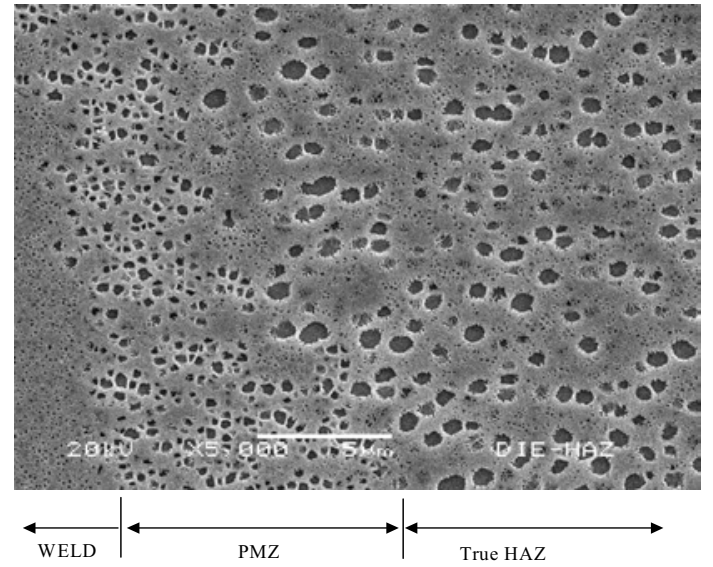

Figure 2: Gamma prime structure of EB welded DS GTD-141 joint.
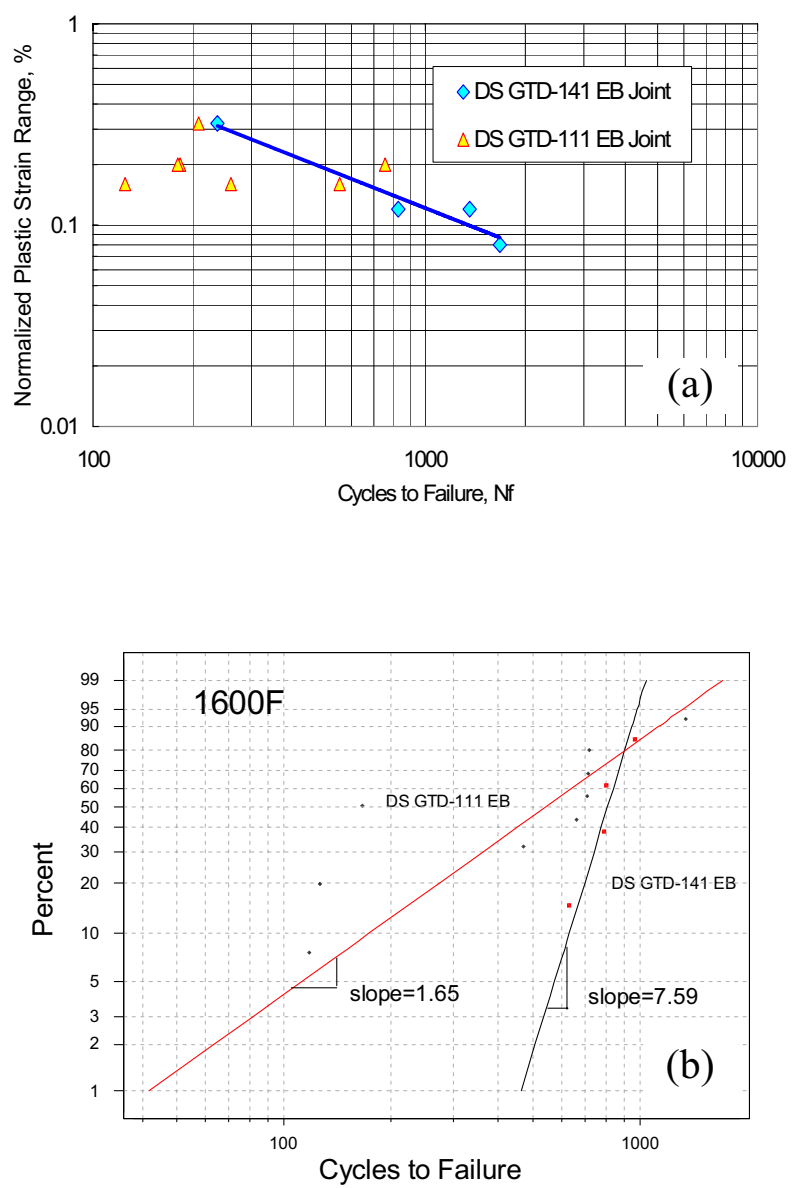

Figure 3: (a) LCF life and (b) Weibull plot of DS GTD-111 and DS GTD-141 EB weld joints.
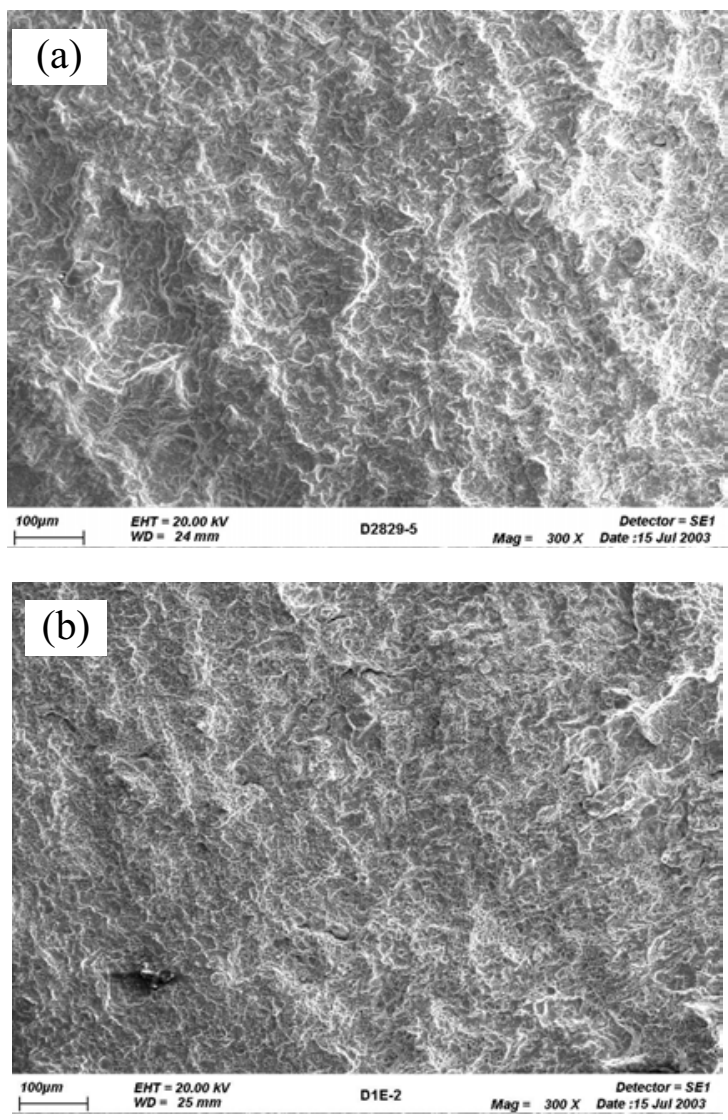

Figure 4: Fracture surface of LCF specimens at 1600F (a) DS GTD-111 ${ }^{\mathrm{TM}}$ EB weld joint, (b) DS GTD-141 EB weld joint.

joints showed a mixed fracture mode of cleavage and fatigue striation in both alloys. However, DS GTD-141 joints exhibited more fatigue crack growth and cleavage fracture, which is consistent with the microstructural observations.

\section{Equiaxed Alloys}

The equiaxed slabs were also welded using the EB process in a similar fashion. Fig. 5 shows the gamma prime morphology of GTD-141 EB weld joint from the weld zone to HAZ. Due to the rapid cooling from the welding temperature, the weld zone shows fine cooling gamma prime. A narrow $5 \mu \mathrm{m}$ wide band can be seen along the fusion line. It consists of small gamma prime and fine cooling gamma prime. This band is defined as the "partially melted zone" (PMZ) that separates the weld zone from the true HAZ. Liquation cracks can initiate from the PMZ and extend to the true HAZ in an EB weld joint. A duplex gamma prime structure can be seen in the true HAZ that is similar to the DS GTD- $111^{\mathrm{TM}}$.

The LCF data of EB weld joints of GTD-141 and the data from the equiaxed GTD-141 parent metal are shown in Fig. 6. The data indicate that the LCF life of EB welded equiaxed GTD-141 joint is the same as the parent metal. This result is different from that of the weld joints of directionally solidified alloys, in which weld joints generally exhibit significant knockdown in LCF life from the parent metal. Because the fusion zone always 
has an equiaxed grain structure, a modulus mismatch exists in the weld joint of a directionally solidified alloy. This results in a stress concentration factor.

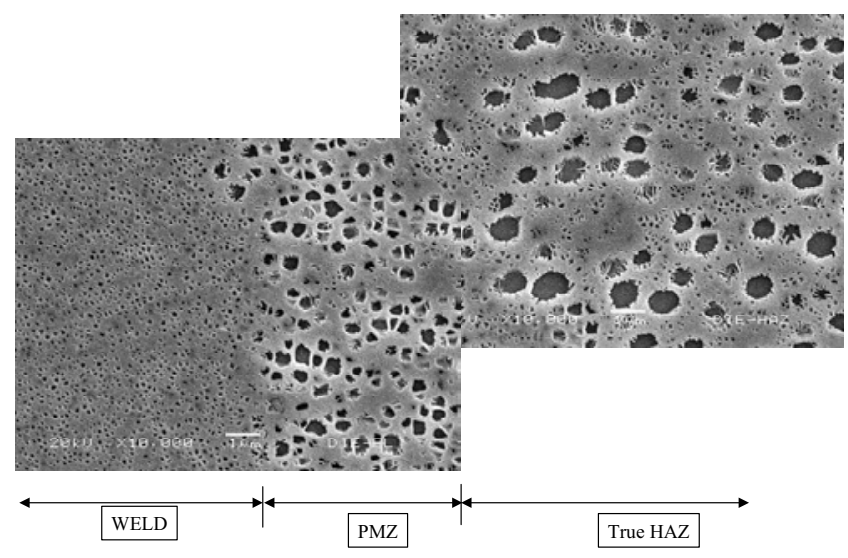

Figure 5: Microstructure across the weld joint of equiaxed GTD141

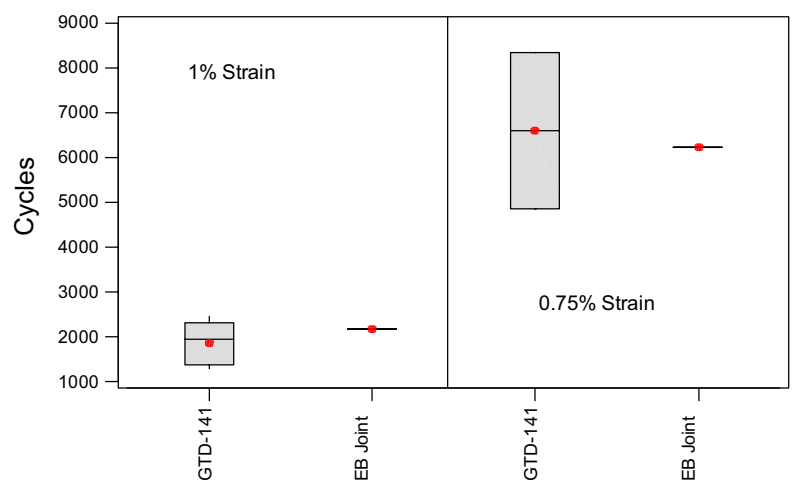

Figure 6: Comparison of LCF lives between GTD-141 parent metal and EB weld joint.

Therefore, a knockdown factor in LCF life is expected for the weld joint of directionally solidified alloy. For an equiaxed alloy, the weld zone has the same grain structure as the parent metal. Due to the high cooling rate, the weld zone usually has a fine grain structure and is free from blocky eutectic phases and carbide networks. When a defect free weld is made, it is possible for the weld joint of an equiaxed alloy to reach the same LCF life as the parent metal.

\section{Hardfacing}

Hardfacing is typically applied to the later stage bucket tip shrouds to protect buckets from wear damage. For GTD-141 to be a satisfactory substitute for GTD- $111^{\mathrm{TM}}$, the alloy must possess adequate weldability during the hardfacing process. The metallurgical issues with hardfacing include HAZ cracking, reheat cracking, and insufficient surface hardness. To evaluate the effect of $\mathrm{Nb}$ on hardfacing, laser hardfacing was conducted. The coupons were made from equiaxed GTD- $111^{\mathrm{TM}}$ and GTD-141. Solution heat-treatment was conducted before the hardfacing. After hardfacing, the coupons were heated to the solution temperature and rapidly quenched to room temperature to check for cracking susceptibility.

Examination of hardfacing coupons found that the fusion zone cracks were similar in the two alloys, which indicates a consistent hardfacing process. Fig. 7 shows the typical interface microstructure of hardfacing coupons. However, the number of HAZ cracks and the total HAZ crack length in GTD-141 coupons were significantly decreased compared with GTD$111^{\mathrm{TM}}$ coupons. Fig. 8 compares the crack formation tendency of two alloys. Fig. 9 shows the hardness across the hardfacing interface. Both alloys exhibited satisfactory hardfacing hardness measurements. In addition to laser hardfacing, plasma and tungsten inert gas welding (TIG) are often used as the hardfacing processes. To verify the response of GTD-141 to different hardfacing processes, TIG and plasma hardfacing were performed on a turbine bucket. TIG hardfacing showed less cracks than the plasma process. However, both processes met maximum crack length requirement for the part. Fig. 10 shows the typical microstructure of TIG and plasma hardfacing.
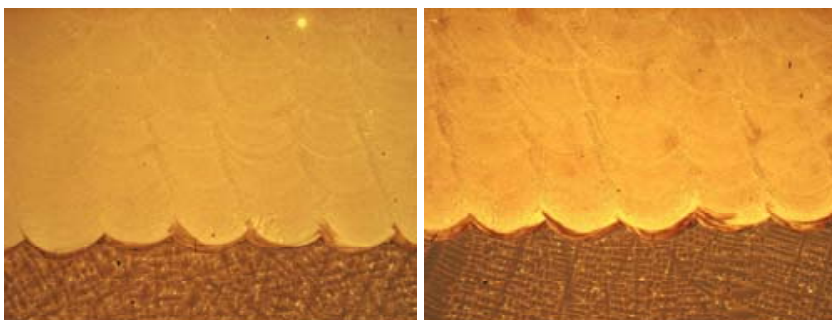

$50 \mathrm{x}$

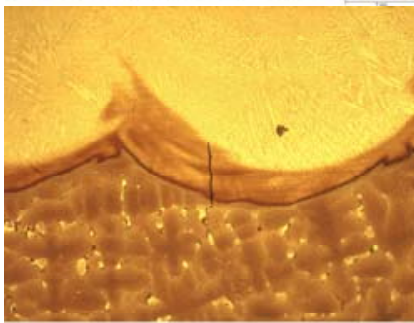

GTD-111

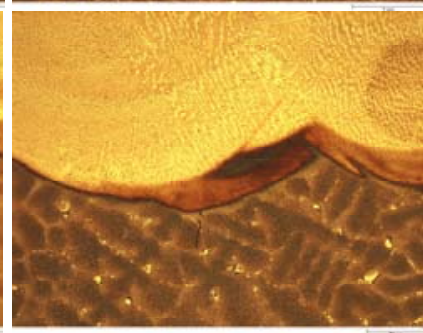

GTD-141
Figure 7: Interface microstructure of hardfacing coupons. 

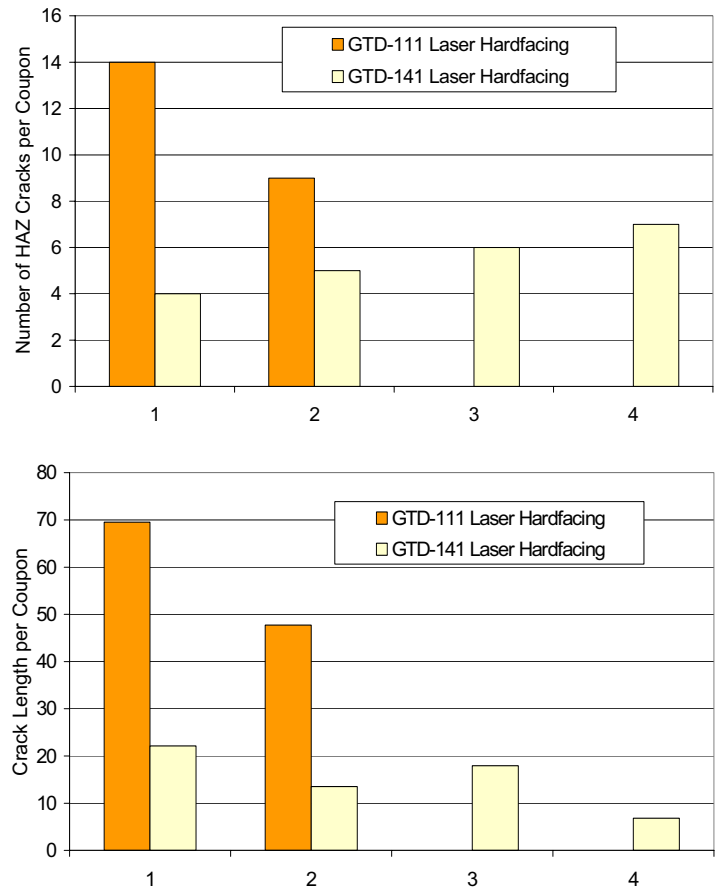

Figure 8: Comparison of hardfacing cracks.

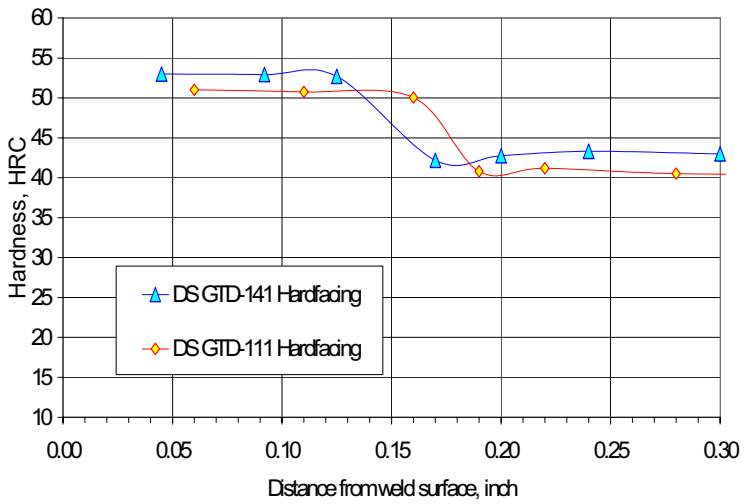

Figure 9: Hardness profile of hardfacing coupons.
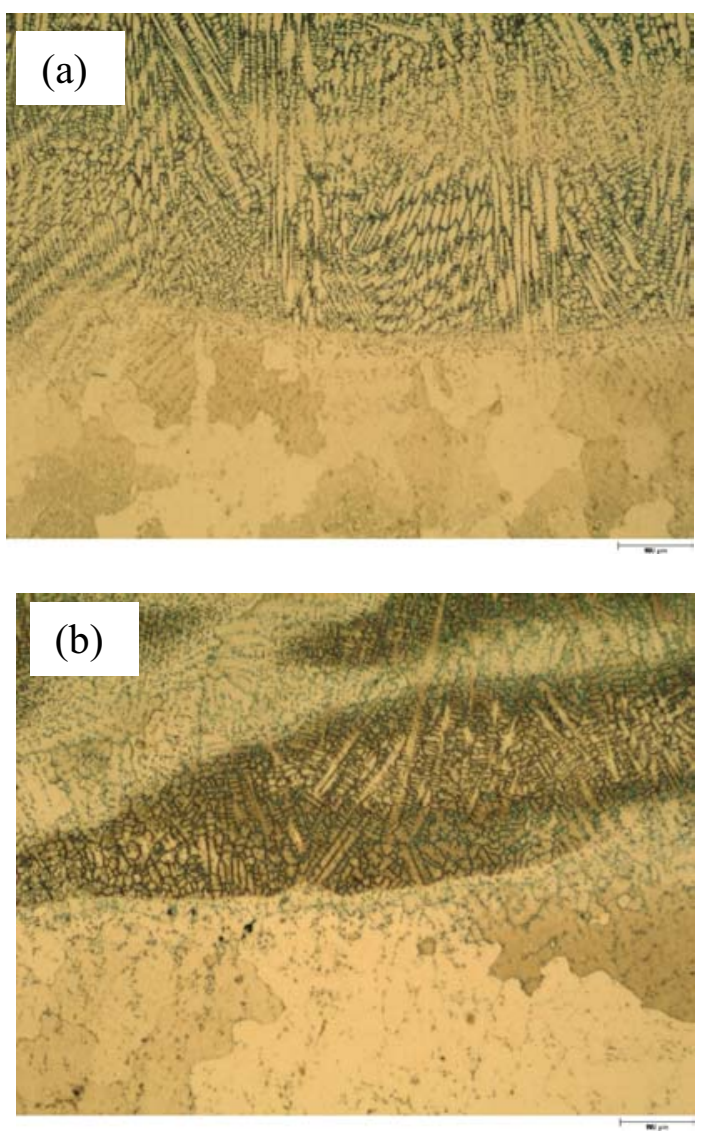

Figure 10: Typical microstructure (a) TIG and (b) plasma hardfacing of GTD-141.

\section{$\underline{\text { Spot-Varestraint Test }}$}

The Spot-Varestraint tests were performed on both directionally solidified and equiaxed alloys. The test matrix is shown in Table 2. Fig. 11 shows the testing results. It does not appear that the variations in $\mathrm{Ta}$ and $\mathrm{Nb}$ examined in this study had a strong effect on the amount of cracking in the weld metal and HAZ for GTD- $111^{\mathrm{TM}}$ and GTD-141. This could attribute to the severe testing condition. Because these alloys containing about $60 \%$ gamma prime are highly sensitive to HAZ cracking, it may be helpful to perform the test at lower strain level. However, a more significant effect was found in the amount of cross-weld cracking which was observed in the baseline GTD- $111^{\mathrm{TM}}$, both in the directionally solidified and the equiaxed conditions. All but one of the baseline GTD- $111^{\mathrm{TM}}$ coupons cracked all the way across the weld. None of the coupons in which $\mathrm{Nb}$ replaced Ta cracked across the weld metal. This may indicate that GTD-141 is less sensitive to solidification cracking. Fig. 12 shows typical photos taken from the two alloys. Cracking across the weld zone can be seen in the GTD-111 ${ }^{\mathrm{TM}}$ coupon while GTD-141 coupon did not present any cross-weld cracking. Furthermore, the baseline equiaxed GTD- $111^{\mathrm{TM}}$ coupons had a much longer maximum crack distance (MCD) than GTD-141 coupons. Nb substitution seems to reduce the amount of stored energy released during the Spot-Varestraint test. 
Table 2: Spot Varestraint Testing Matrix

\begin{tabular}{|l|l|l|l|}
\hline Material & Thickness. & $\begin{array}{l}\text { Strain } \\
\%\end{array}$ & Qty \\
\hline DS GTD-141 & 0.2 & $0.8 \& 1.6$ & 4 \\
\hline DS GTD-111 & 0.2 & $0.8 \& 1.6$ & 2 \\
\hline EA GTD-141 & 0.25 & $1 \& 2$ & 2 \\
\hline EA GTD-111 & 0.25 & $1 \& 2$ & 2 \\
\hline
\end{tabular}
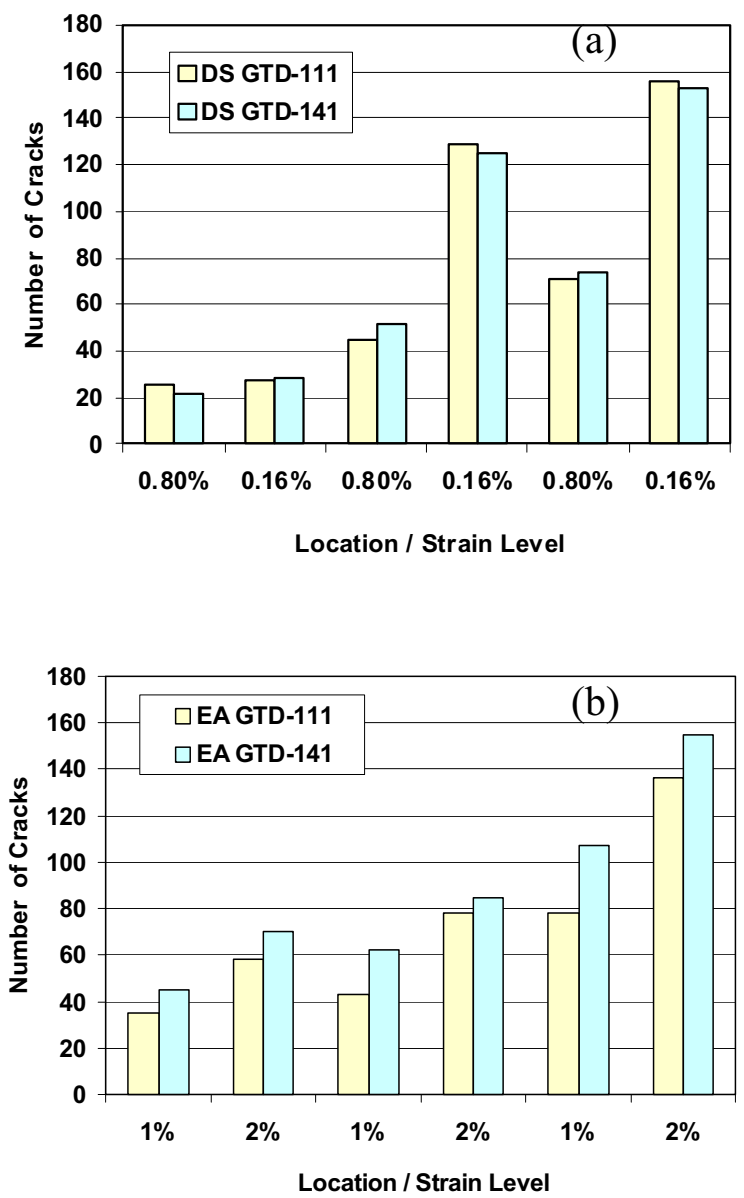

Figure 11: Spot-Varestraint test results (a) DS alloys, (b) equiaxed alloys.
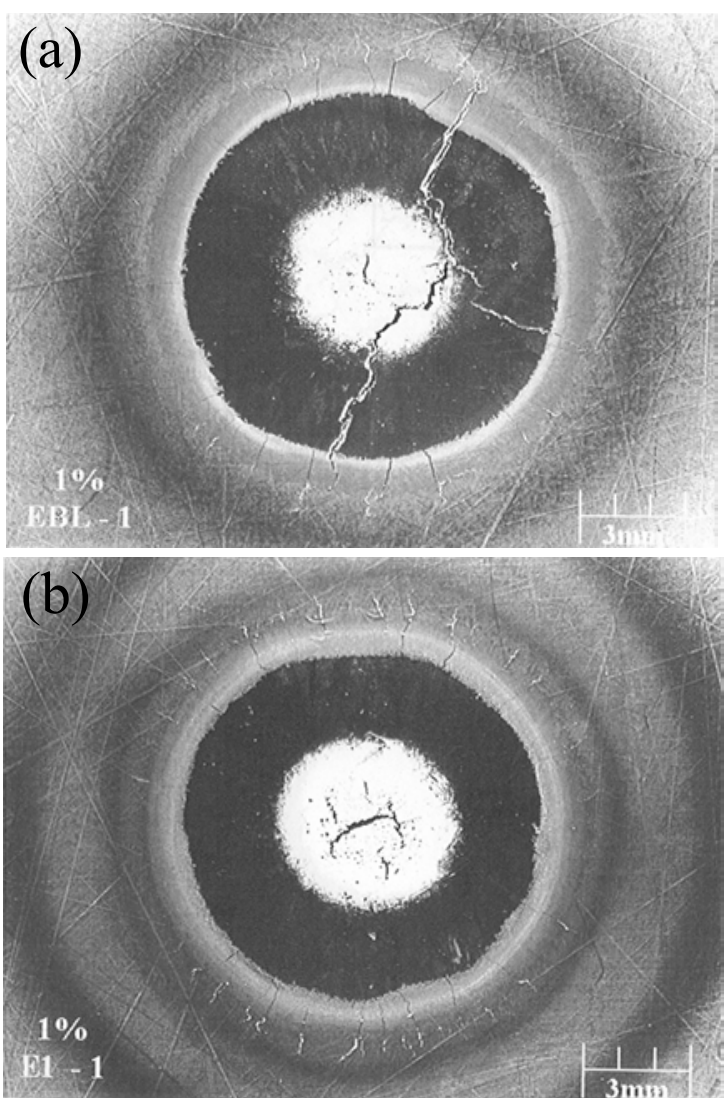

Figure 12: Micrographs taken from Spot-Varestraint test coupons.

\section{Conclusions}

1. $\mathrm{Nb}$ substitution for Ta in GTD-111 ${ }^{\mathrm{TM}}$ did not show any detrimental effect on the fusion zone/HAZ microstructures, or LCF properties of the EB weld joints compared to GTD$111^{\mathrm{TM}}$ baseline. With nearly $60 \%$ vol fraction gamma prime, it was expected that GTD-141 would be as "unweldable" as baseline GTD-111 ${ }^{\mathrm{TM}}$. However, crackfree weld joints can be achieved by using advanced EB welding processes. The LCF life of an equiaxed GTD-141 EB weld joint could be as high as that of the parent metal.

2. GTD-141 helped to reduce HAZ cracks during hardfacing. The benefit is attributed to the improvement in ductility due to the $\mathrm{Nb}$ substitution. The Spot-Varestraint tests revealed that $\mathrm{Nb}$ substitution did not have a strong effect on the HAZ liquation cracking. However, long cracks through the weld zone were reduced. 


\section{Reference}

1. J. H. Wood, D. A. Shores and N. R. Lindblad, US Patent 6416596 B1, July 2002

2. J. H. Wood, D. A. Shores and N. R. Lindblad, US Patent 6428637 B1, Aug. 2002

3. S. L. West, W. A. Baeslack and T. J. Kelly, "Morphology of Weld Heat-Affect Zone Liquation Cracking in TaModified Cast Alloy 718”, Metallography, 23, 1989, P219

4. W. A. Baeslack, S. L. West and T. J. Kelly, "Weld Cracking in Ta-Modified Cast Inconel 718", Scripta Metallurgica, 22, 1988, P729

5. J.S. Zhang, Z.Q. Hu, Y. Murata, M. Morinaga, N. Yukawa, "Effects of Refractory Metals Titanium, Tantalum, and Niobium on Microstructures and Properties", Metallurgical Transactions A 24A, 1993, P2451

6. L. F. Coffin, Trans. ASME 76, p931, 1954 
